\title{
Prophylactic use of antibiotics as per SIGN 104 guidelines versus routine antibiotic prophylaxis for prevention of surgical site infection in clean and clean contaminated ENT surgical procedures: a comparative study
}

\author{
M. Bharath, J. R. Galagali*, Awadhesh Kumar Mishra, Ajay Mallick, E. Nikhilesh
}

Department of Otorhinolaryngology and Head Neck Surgery, Army College of Medical Sciences and Base Hospital, Delhi Cantt, New Delhi, India

Received: 22 August 2019

Revised: 08 November 2019

Accepted: 14 November 2019

\section{*Correspondence:}

Dr. J. R. Galagali,

E-mail: jeevan.galagali@gmail.com

Copyright: ( $)$ the author(s), publisher and licensee Medip Academy. This is an open-access article distributed under the terms of the Creative Commons Attribution Non-Commercial License, which permits unrestricted non-commercial use, distribution, and reproduction in any medium, provided the original work is properly cited.

\section{ABSTRACT}

Background: Many clinicians continue to use antibiotic prophylaxis routinely in all surgical procedures, ignoring the guidelines issued by policy makers. In this prospective study we compared the rate of surgical site infection (SSI) in patients who received prophylactic antibiotics as a routine; with the rate of SSI in patients getting antibiotics strictly as per SIGN 104 Guidelines, for clean and clean contaminated procedures.

Methods: The study population comprised 235 patients. Group A consisted of 119 patients having 77 (65\%) males and $42(35 \%)$ females while Group B had 116 patients - $71(61 \%)$ males and $45(39 \%)$ females. Group A received routine antibiotic prophylaxis in all cases, while Group B received antibiotic prophylaxis as per SIGN 104 guidelines only. Both the groups were followed up for one month post-operatively for SSI and complications.

Results: SSI occurred in 2 patients $(1.68 \%)$ in Group A and in $3(2.59 \%)$ patients in Group B. There was no significant difference in the rate of SSI between the two groups $(p=0.68)$. Procedure wise maximum SSI occurred in tympanoplasty and laryngectomy. Due to infection one case of tympanoplasty had graft failure and one case of laryngectomy had delayed wound healing. No major complications related to infection or antibiotic use occurred in either group.

Conclusions: Selective use of antibiotic prophylaxis as per SIGN 104 Guidelines does not lead to increase in SSI in clean and clean contaminated ENT procedures.

Keywords: Antibiotic prophylaxis, Clean procedure, Clean contaminated procedure, ENT procedures, Surgical site infection

\section{INTRODUCTION}

The term surgical site infection (SSI) is used to encompass the surgical wound and infections involving the body cavity, bones, joints, meninges and other tissues involved in the operation. In procedures that require the insertion of implants or prosthetic devices the term also encompasses infections associated with these devices. ${ }^{1}$
SSI is defined as infections occurring up to 30 days after surgery (or up to one year after surgery in patients receiving implants) and affecting either the incision or deep tissue at the operation site. It remains a significant clinical problem due to associated mortality and morbidity. $^{2}$

Common organisms causing SSI in oropharyngeal procedures include Pepto streptococcus, Staphylococcus 
aureus, Clostridium perfringens, Bacteroids, Haemophilus influenzae, Klebsiella, Pseudomons and Proteus. In nasal surgeries S. aureus, Klebsiella spp., and Escherichia coli are common pathogens for SSI; while procedures on ears may be complicated by infection with Haemophilus, Pseudomonas and Staphylococcus. The choice of antibiotic for preventing SSI will be influenced by its effectiveness against the likely pathogen. The chosen antimicrobial should be bactericidal, cause minimal side effects and have a minimal impact on the local colonizers of the patient and the hospital. ${ }^{3}$ While the need of antibiotics is obvious in contaminated and dirty wounds, in clean and clean contaminated wounds their role is debatable.

Antibiotic prophylaxis for prevention of SSI essentially refers to the practice of administering an antibiotic before contamination of previously sterile spaces and fluids, with an aim to eliminate transient (pathogenic) organisms which may colonize the tissues and inhibit the growth of resident (commensal) microbes. ${ }^{4}$

It would be reasonable to employ antibiotic prophylaxis for procedures which are associated with high risk of infection or where infection can cause serious problems. ${ }^{5}$ However, it has been noted in the past that prolonged antibiotic prophylaxis does not decrease surgical infection and is associated with higher levels of bacterial resistance. ${ }^{6}$ Later studies also showed that prevalence of antibiotic-resistant bacteria increases by the use of antibiotics. $^{7}$

Antibiotics can also predispose the patients to serious complications like infection by clostridium difficile which can cause colitis. ${ }^{8}$ Indiscriminate use of antibiotics can also cause toxic reactions. ${ }^{9}$ Hence, judicious use of antibiotics is necessary.

NHS of Scotland has recommended Scottish Intercollegiate Guidelines Network 104 Guidelines (SIGN 104) for antibiotic prophylaxis in various surgical procedures in order to rationalize the use of prophylactic antibiotics, which are becoming popular Worldwide. ${ }^{1}$

Many countries have formulated their own guidelines with similar aim. Even hospitals are having their own antibiotic policy. World Health Organisation has also issued global guidelines on this issue. ${ }^{10}$ In India, Indian Council of Medical Research has issued guidelines for microbial use with a chapter on prophylaxis for surgery. However, it has not given procedure wise recommendations and also has not commented in which procedures antibiotic prophylaxis is not recommended. ${ }^{11}$ SIGN 104 guidelines are easier to follow as these have clearly indicated whether or not prophylactic antibiotics are recommended in a particular procedure.

Despite the availability of these guidelines many centres continue to use antibiotics peri -operatively as a routine fearing increase in the rate of post-operative SSI, if antibiotics are not used. In a study conducted by Valdez et al, most physicians reported routinely prescribing antibiotics either preoperatively or postoperatively for 12 of the 17 procedures included in their questionnaire despite agreeing that there is not enough evidence to support their use. ${ }^{12}$

Although there are some studies in the literature demonstrating the efficacy of these guidelines, most of these are retrospective audits. ${ }^{3}$ Also, there are not many prospective comparative studies conducted in our population on this issue, hence, further studies are warranted.

In this study we have prospectively followed our patients and compared the rate of SSI in patients who received prophylactic antibiotics as a routine; with the rate of SSI in patients getting antibiotics strictly as per SIGN 104 Guidelines, for clean and clean contaminated procedures.

\section{METHODS}

This study was conducted at Army College of Medical Sciences and Base Hospital, Delhi Cantt, India; a territory care centre from July 2018 to May 2019. All patients planned for various ENT surgeries at our centre were considered for the study. Informed consent for surgery as well as for participation in the study was obtained from all the patients. Ethical clearance for the study was provided by the institutional ethics committee and the study was approved by the scientific review committee of our hospital. Detailed history, clinical examination and investigative work-up were carried out as per the requirement of the surgery planned.

\section{Inclusion criteria}

All cases undergoing elective ENT surgery falling in the class of clean and clean contaminated procedures.

\section{Exclusion criteria}

Patients with uncontrolled diabetes mellitus, immunecompromised state, congenital heart disease, prosthetic valve or with history of infective endocarditis were excluded. Patients with history of previous irradiation or steroidal therapy; pre-existing infection or receiving antibiotics were also not included. Other causes for exclusion were contaminated and dirty class of procedures, and known allergy to the antibiotics used.

\section{Group allocation and randomization}

After fulfilling inclusion and exclusion criteria, consenting patients were consecutively recruited to the study and were allocated to either group A or B using simple randomization. For this purpose, we used online randomization using the website www.random.org. Before the enrollment of the patients we generated a list of random numbers by asking the random integer 
generator application at this website to generate 500 numbers between 1 and 500 formatted in two columns. This gave us two columns of random numbers which we named as group A and B respectively. Once a patient was enrolled in the study, a resident again generated a random number, this time a single number, by asking the application to generate one number between 1 and 500 formatted in 1 column. The single number so obtained was matched with the table of numbers already made at the onset of study and the column in which this number was found was the group assigned to that patient.

\section{Intervention}

In Group A, we administered prophylactic antibiotics as a routine in all cases in the form of amoxycillin clavulanate, in the dose of $25 \mathrm{mg} / \mathrm{kg}$ (maximum $1000 \mathrm{mg}$ ) of amoxycillin given intravenously before the induction of anaesthesia, after sensitivity test and continued 12 hourly for 24 hours in the post-operative period. If allergic to penicillins or beta lactums, azithromycin 10 $\mathrm{mg} / \mathrm{kg} \quad$ (maximum $500 \mathrm{mg}$ ) was administered intravenously before induction of anaesthesia and in the morning of first post-operative day. In procedures on oral cavity and oropharynx, metronidazole $15 \mathrm{mg} / \mathrm{kg}$ (maximum $500 \mathrm{mg}$ ) was also given intravenously on the day of surgery before induction of anaesthesia and continued 8 hourly for 24 hours.

In Group B, prophylactic antibiotics were administered only for those procedures, for which antibiotic prophylaxis has been recommended by SIGN 104 guidelines. The dosage and route of administration was also followed as per the SIGN 104 guidelines. ${ }^{1}$ All the patients underwent elective surgeries as planned. All were observed post-operatively till the discharge from hospital and then followed up at 7 days and 30 days after discharge. SSI and any complications were looked for during each observation.

\section{Main outcome measures}

Primary outcome measure of this study was SSI. Diagnosis of SSI was made as per guidelines of the Centers for Disease Control and Prevention, Atlanta, Georgia, United States of America. ${ }^{2}$ Secondary outcomes were duration of hospital stay, drug reactions and complications.

\section{Statistical analysis}

Statistical analysis was performed using SPSS version 21 (IBM Corporation) software. Descriptive data are presented as mean, Standard Deviation (SD), range and proportions. Student's ' $t$ ' test was used for comparing continuous variables and Chai squared tests for nominal or categorical variables. Rates of infection have been compared using Fischer's exact test. P value of $<0.05$ was considered significant.

\section{RESULTS}

The study population comprised 235 patients - 148 (63\%) males and $87(37 \%)$ females. Group A consisted of 119 patients having $77(65 \%)$ males and $42(35 \%)$ females while Group B had 116 patients - $71(61 \%)$ males and 45 (39\%) females. There was no significant difference between the groups in mean age $(\mathrm{p}=0.46$; $\mathrm{t}$ test $)$ or in gender composition $(\mathrm{p}=0.58$; Chi squared test). A summary of demographic and descriptive data is given in Table 1.

Details of procedure, antibiotics usage and SSI of Group $\mathrm{A}$ and $\mathrm{B}$ are given in Table 2 and 3 respectively. Most common procedures were tympanoplasty, Adenotonsillectomy, septoplasty, DL scopy biopsy, tracheostomy and functional endoscopic sinus surgery. There were no significant differences between the groups in the proportions of procedures performed in each group.

Table 1: Demographic and descriptive statistics of the study.

\begin{tabular}{|lllll|}
\hline Parameter studied & Group A $(\mathbf{n = 1 1 9})$ & Group B $(\mathbf{n = 1 1 6 )}$ & All patients $(\mathbf{n = 2 3 5})$ & P value (Test) \\
\hline Age range (years) & $5-67$ & $6-66$ & $5-67$ & \\
\hline Mean age (years) & 43.2 & 41 & 43 & $0.46(\mathrm{t}$-test) \\
\hline Standard deviation & 11.23 & 12.15 & 12.13 & \\
\hline Male (\%) & $77(65)$ & $71(61)$ & $148(63)$ & $0.58\left(\mathrm{Chi}^{2}\right)$ \\
\hline Female (\%) & $42(35)$ & $45(39)$ & $87(37)$ & \\
\hline Smoking (\%) & $9(7.5)$ & $7(6)$ & $16(6.8)$ & $0.64\left(\mathrm{Chi}^{2}\right)$ \\
\hline Alcohol (\%) & $6(5)$ & $8(6.8)$ & $14(5.9)$ & $0.55\left(\mathrm{Chi}^{2}\right)$ \\
\hline Days of hospital stay mean (SD) & $3.1(1.1)$ & $3.2(1.1)$ & $3.1(1.2)$ & $0.36(\mathrm{t}$-test) \\
\hline
\end{tabular}

Table 2: Details of procedure, antibiotics usage and SSI of Group A (n=119).

\begin{tabular}{|llllll|}
\hline S. No. & Procedure & Total No. & No. received PA & No. did not get PA & No. of SSI \\
\hline $\mathbf{1}$ & Tympanoplasty (fresh and revision) & 16 & 16 & 0 & 1 \\
\hline $\mathbf{2}$ & $\begin{array}{l}\text { Cortical mastoidectomy with } \\
\text { tympanoplasty }\end{array}$ & 11 & 11 & 0 & 1 \\
\hline $\mathbf{3}$ & Septoplasty & 14 & 14 & 0 & 0 \\
\hline
\end{tabular}




\begin{tabular}{|llllll|}
\hline S. No. & Procedure & Total No. & No. received PA & No. did not get PA & No. of SSI \\
\hline $\mathbf{4}$ & FESS & 8 & 8 & 0 & 0 \\
\hline $\mathbf{5}$ & Closed reduction fracture nasal bone & 2 & 2 & 0 & 0 \\
\hline $\mathbf{6}$ & Endoscopic DCR & 4 & 4 & 0 & 0 \\
\hline $\mathbf{7}$ & Augmentation rhinoplasty & 2 & 2 & 0 & 0 \\
\hline $\mathbf{8}$ & Biopsy mass nasopharynx & 2 & 2 & 0 & 0 \\
\hline $\mathbf{9}$ & Adenotonsillectomy & 15 & 15 & 0 & 0 \\
\hline $\mathbf{1 0}$ & DL scopy and biopsy & 11 & 11 & 0 & 0 \\
\hline $\mathbf{1 1}$ & Micolaryngeal surgery laser assisted & 6 & 6 & 0 & 0 \\
\hline $\mathbf{1 2}$ & Removal of foreign body oesophagus & 4 & 4 & 0 & 0 \\
\hline $\mathbf{1 3}$ & Total laryngectomy with PMMC flap & 2 & 2 & 0 & 0 \\
\hline $\mathbf{1 4}$ & Medial maxillectomy & 3 & 3 & 0 & 0 \\
\hline $\mathbf{1 5}$ & Elective tracheostomies & 11 & 11 & 0 & 0 \\
\hline $\mathbf{1 6}$ & Abscess incision and drainage & 3 & 3 & 0 & 0 \\
\hline $\mathbf{1 7}$ & Thyroidectomy (beningn) & 4 & 4 & 0 & 0 \\
\hline $\mathbf{1 8}$ & Thyroidectomy (malignant) & 1 & 1 & 0 & \\
\hline
\end{tabular}

$\mathrm{PA}=$ Prophylactic antibiotics, SSI=Surgical site infection, No.=Number.

Table 3: Details of procedure, antibiotics usage and SSI of Group B ( $n=116)$.

\begin{tabular}{|c|c|c|c|c|c|}
\hline Procedure & $\begin{array}{l}\text { Total } \\
\text { No. }\end{array}$ & $\begin{array}{l}\text { SIGN } 104 \\
\text { guideline; R or NR }\end{array}$ & $\begin{array}{l}\text { No. received } \\
\text { PA }\end{array}$ & $\begin{array}{l}\text { No. did } \\
\text { not get PA }\end{array}$ & $\begin{array}{l}\text { No. of } \\
\text { SSI }\end{array}$ \\
\hline Tympanoplasty (fresh and revision) & 20 & NR & 0 & 20 & 1 \\
\hline Cortical mastoidectomy with tympanoplasty & 13 & $\mathrm{R}$ & 13 & 0 & 1 \\
\hline Septoplasty & 16 & NR & 0 & 16 & 0 \\
\hline FESS & 10 & NR & 0 & 10 & 0 \\
\hline Closed reduction fracture nasal bone & 1 & NR & 0 & 1 & 0 \\
\hline Endoscopic DCR & 5 & NR & 0 & 5 & 0 \\
\hline Augmentation rhinoplasty & 1 & $\mathrm{R}$ & 1 & 0 & 0 \\
\hline Biopsy mass nasopharynx & 1 & $\mathrm{R}$ & 1 & 0 & 0 \\
\hline Adenotonsillectomy & 13 & NR & 0 & 13 & 0 \\
\hline DL scopy and biopsy & 9 & $\mathrm{R}$ & 9 & 0 & 0 \\
\hline Micolaryngeal surgery laser assisted & 5 & $\mathrm{R}$ & 5 & 0 & 0 \\
\hline Removal of foreign body oesophagus & 3 & $\mathrm{NR}$ & 0 & 3 & 0 \\
\hline Total laryngectomy with PMMC flap & 2 & $\mathrm{R}$ & 2 & 0 & 1 \\
\hline Medial maxillectomy & 2 & $\mathrm{R}$ & 2 & 0 & 0 \\
\hline Elective tracheostomies & 7 & NR & 0 & 7 & 0 \\
\hline Abscess incision and drainage & 4 & $\mathrm{R}$ & 4 & 0 & 0 \\
\hline Thyroidectomy (beningn) & 3 & NR & 0 & 3 & 0 \\
\hline Thyroidectomy (malignant) & 1 & $\mathrm{R}$ & 1 & 0 & 0 \\
\hline
\end{tabular}

$\mathrm{PA}=$ Prophylactic antibiotics, SSI=Surgical site infection, $\mathrm{R}=$ Recommended, NR=Not recommended, No.=Number.

Prophylactic antibiotics were administered in 119 (100\%) patients in Group A; but only in $38(32.76 \%)$ patients in Group B. 78 (67.24\%) patients in Group B did not receive any prophylactic antibiotic as it was not recommended by SIGN104 guidelines.

SSI occurred in 2 patients in Group A and in 3 patients in Group B. There was no significant difference in the rate of SSI between the two groups ( $\mathrm{p}=0.68$; Fisher's Exact Test). Procedure wise maximum SSI occurred in tympanoplasty and laryngectomy. Due to infection one case of tympanoplasty had graft failure and one case of laryngectomy had delayed wound healing.
One patient in Group A had drug reaction in the form of mild urticaria which was self-limiting. No other complication attributable to usage of antibiotics or infection occurred in either group.

Average length of hospital stay in Group A was 1.52 days and in Group B 1.8 days. The difference was not significant $(\mathrm{p}=0.30$, t test).

\section{DISCUSSION}

Many studies have indicated beneficial effects of prophylactic administration of antibiotics. This practice can decrease postoperative morbidity leading to shorter 
period of hospitalization, and reduce costs which would have been incurred, if the infections occurred. ${ }^{13-15}$ However, researchers have also cautioned that the antibiotics should be discontinued 24 hours after surgery. Prolonged antibiotics use can lead to bacterial resistance and increased hospital costs. ${ }^{16}$ Therefore, injudicious use of antibiotics to prevent SSI may not be justified. In fact, indiscriminate use of prophylactic antibiotics may be more damaging to the patient. Hence, guidelines for rational use of prophylactic antibiotics, like SIGN 104, are the need of the hour.

In our study, use of prophylactic antibiotics strictly as per the recommendation of SIGN 104 guidelines did not lead to increased SSI as compared to the patients in whom these were routinely used. This led to drastic reduction in antibiotic usage in group B (just $32.76 \%$ compared to $100 \%$ usage in group A) without significant increase in SSI. Length of hospital stay also was comparable between the two groups; and no serious complications due to antibiotics occurred in any group.

Similar results have been achieved by some earlier studies. Patel et al in a state of the art review pointed out the lack of evidence to support routine antibiotic prophylaxis in many surgeries and recommended it for selected surgeries like complex septorhinoplasty, skull base surgery (anterior and lateral), clean-contaminated otologic surgery (cholesteatoma, purulent otorrhea), and clean-contaminated head and neck surgery (violation of aerodigestive tract, free flaps). They also commented that antibiotic overuse and variability among providers may be due to lack of formal practice guidelines. ${ }^{17}$

The clinicians who hesitate to follow these guidelines, despite accepting the effectiveness of these guidelines in prevention of SSI, need to appreciate that prophylactic antibiotics are only an adjunct to good surgical technique and therefore cannot replace it. There is a multitude of factors responsible for SSI which also must be taken care of. These may be patient-related like age, nutritional status, diabetes, smoking, obesity, altered immune response, or procedure-related like duration of surgical scrubbing, preoperative shaving, preoperative skin preparation, duration of operation, operating room ventilation, quality of sterilization of surgical instruments, surgical technique, poor haemostasis, tissue trauma etc. ${ }^{2}$

The centers for disease control and prevention guidelines for the prevention of SSIs also emphasise the importance of good patient preparation, aseptic practice, and attention to surgical technique. According to their guidelines, antimicrobial prophylaxis is also indicated in specific circumstances. ${ }^{18}$ Furthermore, increased duration of prophylaxis has failed to decrease infection in many of the patients belonging to high risk groups. ${ }^{19,20}$ Panda et al also concluded in their study that short-term antibiotic prophylaxis in clean and clean-contaminated cases is feasible and as effective as long-term prophylaxis.
Correction of anemia and hypoalbuminemia, weight reduction, and avoidance of tobacco can prevent SSI. ${ }^{21}$

Large-scale use of prophylactic antibiotics in clean and clean-contaminated ear surgery has not been found to be helpful in reducing postoperative complications. ${ }^{22}$ Similarly, Habibi et al did not recommend routine use of prophylactic antibiotics after evaluation of 1010 procedures in their study. ${ }^{23}$

There is no universal agreement on the choice of antibiotic for prophylactic use. For example, cefazolin has been commonly used for antibiotic prophylaxis, but, Otake et al showed in their study that oral azithromycin had equal efficacy as intravenous cefazolin in preventing surgical site infection in tonsillectomy patients. ${ }^{24}$ On the other hand Shkedy et al did not find prophylactic use of cefazolin to reduce post-operative infection in revision clean head neck surgery. ${ }^{25}$

We chose to study the efficacy of SIGN 104 guidelines because we found these quite easy to follow, as these guidelines have clearly spelt out procedure wise, whether to use prophylactic antibiotics or not. Where antibiotic prophylaxis is recommended, the choice of antibiotics and dosage is also spelt out. In comparison to this, other guidelines have given their recommendation for choice of antibiotic for prophylactic use along with dosage for the procedure where these are indicated; but have not indicated where antibiotic prophylaxis should not be used.

Our study has the limitation of smaller number of patients compared to the number actually required for such type of studies. Incidence of SSI in the present-day procedures is as such low due to excellent patient preparation and good surgical techniques. Hence, to get sizable number of patients with SSI will require a very large sample.

\section{CONCLUSION}

We would like to reaffirm the argument that adherence to SIGN 104 guidelines does not increase the incidence of SSI in clean and clean contaminated procedures. Hence, antibiotic prophylaxis in accordance to these guidelines will reduce overall consumption of antibiotics and prevent resistance against the antibiotics.

\section{ACKNOWLEDGEMENTS}

The authors would like to thank all the patients who consented to participate in this study.

Funding: No funding sources Conflict of interest: None declared

Ethical approval: The study was approved by the Institutional Ethics Committee 


\section{REFERENCES}

1. Delbridge SIGN 104: Antibiotic prophylaxis in surgery. July 2008, updated April 2014. Available at: http://www.sign.ac.uk/. Accessed on $24^{\text {th }}$ April 2018.

2. Mangram AJ, Horan TC, Pearson ML, Silver LC, Jarvis WR. Hospital Infection Control Practice Advisory Committee. Guideline for prevention of surgical site infection, 1999. Infect Control Hosp Epidemiol. 1999;20:247-8.

3. American Society of Health-System Pharmacists. ASHP therapeutic guidelines on antimicrobial prophylaxis in surgery. Am J Health Syst Pharm. 1999;56:1839-88.

4. Fennessy BG, Harney M, O’Sullivan MJ, Timon G. Antimicrobial prophylaxis in otorhinolaryngology/head and neck surgery. Clin Otolaryngol. 2007;32:204-7.

5. Fairbanks DN. In: Bayley BJ, Calhoun KH et al. Head and Neck Otolaryngology. Third edition. Philadelphia, Lippincott: Williams and Wilkins; 2001:47-54.

6. Strong MT. Wound infection in otolaryngologic surgery and the inexpediency of antibiotic prophylaxis. Laryngoscope. 1963;73(2):165-84.

7. Goldmann DA, Weinstein RA, Wenzel RP, Tablan OC, Duma RJ, Gaynes RP, et al. Strategies to prevent and control the emergence and spread of antimicrobialresistant microorganisms in hospitals. A challenge to hospital leadership. JAMA. 1996;275(3):234-40.

8. Jobe BA, Grasley A, Deveney KE, Deveney CW, Sheppard BC. Clostridium difficile colitis: an increasing hospital-acquired illness. Am J Surg. 1995;169(5):480-3.

9. Caniello M, Passerotti GH, Goto EY, Voegels RL, Butugan O. Antibiotics in septoplasty: is it necessary? Rev Bras Otorrinolaringol. 2005;71(6):734-8.

10. Global Guidelines For The Prevention Of Surgical Site Infection. ISBN 978924154988 2. World Health Organization; 2016.

11. Treatment Guidelines for Antimicrobial Use in Common Syndromes. Indian Council of Medical Research. Department of Health Research, New Delhi, India; 2017:88-96.

12. Valdez TA, Marvin K, Bennett NJ, Lerer T, Nolder AR, Buchinsky FJ. Current trends in perioperative antibiotic use. Otolaryngol Head Neck Surg. 2014;152(1):63-6.

13. Saleh AM, Torres KM, Murad MH, Erwin PJ, Driscoll CL. Prophylactic perioperative antibiotic use in endoscopic sinus surgery: a systematic review and meta-analysis. Otolaryngol Head Neck Surg. 2012;146(4):533-8.

14. Simo R, French G. The use of prophylactic antibiotics in head and neck oncological surgery. Curr Opin Otolaryngol Head Neck Surg. 2006;14(2):55-61.
15. Man LX, Beswick DM, Johnson JT. Antibiotic prophylaxis in uncontaminated neck dissection. Laryngoscope. 2011;121(7):1473-7.

16. Kreutzer K, Storck K, Weitz J. Current evidence regarding prophylactic antibiotics in head and neck and maxillofacial surgery. Biomed Res Int. 2014:2014:879437.

17. Patel PN, Jayawardena ADL, Walden RL, Penn EB, Francis DO. Evidence-based use of perioperative antibiotics in otolaryngology. Otolaryngol Head Neck Surg. 2018;158(5):783-800.

18. Owens CD, Stoessel K. Surgical site infections: epidemiology, microbiology and prevention. J Hospital Infect. 2008;70(S2):3-10.

19. Lotfi CJ, Cavalcanti Rde C, Costa e Silva AM. Risk factors for surgical-site infections in head and neck cancer surgery. Otolaryngol Head Neck Surg. 2008;138(1):74-80.

20. Yang CH, Chew KY, Solomkin JS, Lin PY, Chiang YC, Kuo YR. Surgical site infections among high-risk patients in clean-contaminated head and neck reconstructive surgery: concordance with preoperative oral flora. Ann Plast Surg. 2013;71 Suppl 1:S55-60.

21. Panda NK, Shafi M, Patro SK, Bakshi J, Verma RK. Changing trends in antibiotic prophylaxis in head and neck surgery: Is short-term prophylaxis feasible?. J Head Neck Physicians Surg. 2016;4:42-8.

22. Verschuur HP, de Wever W, van Benthem PP. Antibiotic prophylaxis in clean and clean-contaminated ear surgery. Cochrane Database of Syst Reviews. 2004:3Art.No.:CD003996.

23. Habibi AF, Banan R, Alizadeh Y, Leyli EK, Hajjan A, Ramezani H, et al. Prophylactic antibiotics prescription in ear, nose, throat and ophthalmologic procedures; an Iranian university hospital situational analysis. Electron J Gen Med. 2018;15(3):em42.

24. Otake H, Suga K, Suzuki H, Nakada T, Kato K, Yoshida $\mathrm{T}$, et al. Antimicrobial prophylaxis in tonsillectomy: the efficacy of preoperative single-dose oral administration of azithromycin in preventing surgical site infection. Acta Otolaryngol. 2014;134(2):181-4.

25. Shkedy Y, Stern S, Nachalon Y, Levi D, Menasherov I, Reifen E, et al. Antibiotic prophylaxis in clean head and neck surgery: A prospective randomised controlled trial. Clin Otolaryngol. 2018;43(6):1508-12.

Cite this article as: Bharath M, Galagali JR, Mishra AK, Mallick A, Nikhilesh E. Prophylactic use of antibiotics as per SIGN 104 guidelines versus routine antibiotic prophylaxis for prevention of surgical site infection in clean and clean contaminated ENT surgical procedures: a comparative study. Int J Otorhinolaryngol Head Neck Surg 2020;6:106-11. 